\title{
Carbon-based solid-liquid lubricating coatings for space applications-A review
}

\author{
Xiaoqiang FAN ${ }^{1,2}$, QunJi XUE ${ }^{1}$, Liping WANG ${ }^{1, *}$ \\ ${ }^{1}$ State Key Laboratory of Solid Lubrication, Lanzhou Institute of Chemical Physics, Chinese Academy of Sciences, Lanzhou, 730000, \\ P. R. China \\ ${ }^{2}$ University of Chinese Academy of Sciences, Beijing100039, P. R. China \\ Received: 26 January 2015 / Revised: 09 March 2015 / Accepted: 12 March 2015 \\ (C) The author(s) 2015. This article is published with open access at Springerlink.com
}

\begin{abstract}
Despite continuous improvements in machine elements over the past few decades, lubrication issues have impeded human exploration of the universe because single solid or liquid lubrication systems have been unable to satisfy the ever-increasing performance requirements of space tribology. In this study, we present an overview of the development of carbon-based films as protective coatings, with reference to their high hardness, low friction, and chemical inertness, and with a particular focus on diamond-like carbon (DLC) films. We also discuss the design of carbon-based solid-liquid synergy lubricating coatings with regards to their physicochemical properties and tribological performance. Solid-liquid composite coatings are fabricated via spinning liquid lubricants on solid lubricating films. Such duplex lubricating coatings are considered the most ideal lubrication choice for moving mechanical systems in space as they can overcome the drawback of adhesion and cold-welding associated with solid films under harsh space conditions and can minimize the crosslinking or chain scission of liquid lubricants under space irradiation. State of the art carbon-based solid-liquid synergy lubricating systems therefore holds great promise for space applications due to solid/liquid synergies resulting in superior qualities including excellent friction reduction and anti-wear properties as well as strong anti-irradiation capacities, thereby meeting the requirements of high reliability, high precision, high efficiency, and long lifetime for space drive mechanisms.
\end{abstract}

Keywords: diamond-like carbon; graphene; ionic liquids; space irradiation; boundary lubrication

\section{Introduction}

Solid lubricating coatings are highly regarded in scientific and industrial communities due to their exceptional chemical inertness, high mechanical strength and hardness, and excellent friction reduction and wear resistance properties. They are primarily considered as hard protective coatings, which provide low friction and wear by minimizing abrasion, shear, and adhesion; however, they cannot reach the levels of long-term reliability and safe operation required for space drive mechanisms under high vacuum,

\footnotetext{
* Corresponding author: Liping WANG.

E-mail: lpwang@licp.cas.cn
}

high-energy irradiation, alternate high/low temperature, high speeds and heavy loads because wear tracks cannot be immediately replenished. In contrast, liquid lubricants possess some unique advantages including ease of wear replenishment, low mechanical noise, and an ability to remove wear debris. Disadvantages of liquid lubricants include volatility, limited carrying capacities, and poor adaption to their environment. In short, while solid lubricating coatings and liquid lubricants have come a long way, they both have their own advantages and disadvantages. The future trend in space tribology is therefore likely to be a combination of solid and liquid lubricating materials to minimize their individual shortcomings through synergistic effects. This review focuses on the development of 
diamond-like carbon (DLC) films, especially DLCbased solid/liquid composite lubricating coatings, under simulated space environments with reference to their tribological performance.

\section{Solid lubricating materials}

Solid lubricating materials have been employed by industries for a long time to achieve low friction and wear under different conditions. Molybdenum disulfide $\left(\mathrm{MoS}_{2}\right)$, tungsten disulfide $\left(\mathrm{WS}_{2}\right)$, hexagonal boron nitride $(\mathrm{HBN})$ and borides $\left(\mathrm{MgB}_{2}\right.$ and $\left.\mathrm{ZnB}_{2}\right)$ have been utilized as lubricant additives, or as strongly-bonded protective coatings deposited by advanced vacuum processes, due to their unique structures and physicochemical properties. These materials form a protective film to prevent friction pairs from coming into direct contact for improved friction reduction and wear resistance performance [1-4]. Some soft metals like $\mathrm{Cu}, \mathrm{Ag}, \mathrm{Sn}$ and $\mathrm{Au}$ are also used on sliding surfaces as lubricant additives or as soft metallic films for providing low friction coefficients due to their low shear strength $[5,6]$. Compared to other solid lubricants, however, carbon has generated the most interest due to its exceptional properties. Carbon has multiple forms and the property of each form depends on its unique structure [7]. These different carbon forms have been investigated for several decades without exhausting its wonders and challenges. Here, we focus on two special forms of carbon, i.e., $\mathrm{sp}^{3}$ and $\mathrm{sp}^{2}$ hybridized adjoint carbon (i.e., DLC as hard protective coatings) and $\mathrm{sp}^{2}$ hybridized carbon (i.e., graphene and carbon nanotube as promising lubricant additives).

\subsection{Diamond-like carbon films}

Diamond-like carbon films are the most promising carbon-based protective coatings due to outstanding physical, mechanical, biomedical, and tribological properties [8]. Over the past few years, significant progress has been made on the development and understanding of DLC, which enabled them to become one of the most promising engineering materials for various industrial applications, such as manufacturing (razor blades, magnetic hard discs, and scratch-resistant glasses), transportation (critical engine parts, mechanical face seals), microelectronics (microelectromechanical systems), and biomedical fields (invasive and implantable medical devices) [9]. Figure 1 displays the development trend in the number of publications on DLC films from 1980 to 2014, and shows that the characteristics and applications of DLC films are being increasingly researched. In 1993, Möller et al. [10,11] proposed a ternary phase diagram which provided a comprehensive structural and chemical description of DLC using $\mathrm{sp}^{3}$ and $\mathrm{sp}^{2}$ hybridized carbon and hydrogen, and in the following years several excellent review papers have covered the history, deposition techniques, characterization and applications of DLC including hydrogenated amorphous carbon (a-C:H, ta-C:H), hydrogen free amorphous carbon (a-C, ta-C), and metal or non-metal containing DLC [12-14]. Of most importance are the findings that DLC films provide exceptional friction reduction and wear resistance behaviors under various conditions.

Schmellenmeier, one of the earliest pioneers of DLC technology, produced carbon films back in 1953, although it wasn't until the 1990s that systematic research on the mechanical and tribological characterization of DLC began $[15,16]$. These studies confirmed that the friction coefficients of DLC films were low and found that such films were sensitive to the testing environment as DLC films showed relatively poor tribological properties in humid environments, whilst displaying impressive performance in inert or dry testing media. Since then, intensive efforts have

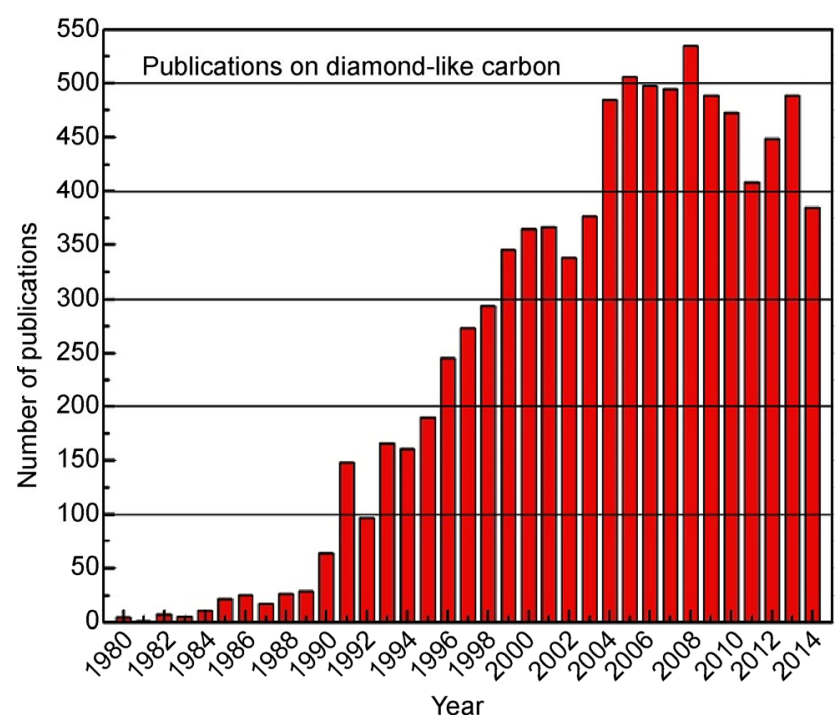

Fig. 1 Number of publications on diamond-like carbon coatings in the period from 1980 to 2014 (data from Scopus database). 
been made to explore the physical and mechanical properties of DLC films, resulting in abundant reports on the outstanding friction reduction and anti-wear behaviors of DLC films, including the relevant mechanisms of these behaviors that depend on the deposition conditions and composition of DLC as well as the testing environment. Grill and Donnet presented reviews on the tribological properties of DLC and doped DLC by the addition of elements (like silicon, nitrogen, fluorine and various metals), and discussed the tribological results and mechanisms in light of their structure and composition as well as the testing environment [17-20]. Holmberg et al. [21] discussed the tribology fundamentals of DLC coatings in a generalized holistic approach to their friction and wear behavior under dry, water- and oil-lubricated conditions, based on a classification of the tribological contact process. Hauert [22] reviewed the industrial and medical applications of DLC coatings taking into account their low friction coefficient, high wear resistance and biological inertness, and also discussed the friction mechanism concerning the so-called transfer layer under different experimental setups and lubrication conditions, while Grill [23] presented an overview of the biomedical characteristics and applications of different amorphous carbon films as protective coatings for improving the friction behavior of biomedical devices due to their excellent tribological properties and biocompatibility. Finally, Kalin et al. [24] analyzed the boundary lubrication behavior of DLC/DLC and doped-DLC/doped-DLC lubricated by oils with extreme-pressure (EP) and anti-wear (AW) additives, and concluded that DLC/DLC contacts showed the lowest friction with oils and the highest friction using oil with an EP additive, and also concluded that the hydrogen content in DLC coatings plays a crucial role in the tribological performance under lubricated and non-lubricated conditions. With the continuous development of deposition techniques and a growing understanding of the relationships between the nature of DLC coatings and their tribological performance under different conditions, some researchers have hoped to develop solid lubricating coatings for vacuum applications, and have carried out a large number of studies in this area. Donnet [25] compared the friction behavior of two kinds of solid lubricating materials (pure $\mathrm{MoS}_{2}$ and hydrogenated DLC) from a pressure range of less than $5 \times 10^{-8} \mathrm{hPa}$ to atmospheric air pressure and found that the friction coefficient of DLC increases from less than 0.01 to $\sim 0.15$ when the pressure increases from ultrahigh vacuum to humid ambient air. This suggests DLC is a potential candidate as a novel solid lubricating material for space applications. As such, the present paper will focus on the tribological performance of DLC films under simulated space environments.

It is a challenge for artificial satellites and spacecrafts installed with various moving mechanical assemblies to maintain reliable and accurate operation in low earth orbit (LEO) or inner space [26]. With the continuous improvement of machine elements over the past few decades, the tribology technique has been a key factor for space exploration, particularly the effects of space environments on lubricating materials. The space environment differs greatly from that on earth, as it contains a high vacuum, temperatures which fluctuate from -120 to $150{ }^{\circ} \mathrm{C}$ due to the influence of sunlight, and harsh space irradiation. For the natural low earth orbit environment, radiation includes electromagnetic irradiation like infrared, visible, ultraviolet (UV), X-ray and gamma ray, and particulate irradiation such as cosmic rays, trapped electrons (EL) and protons (Pr), and solar flares. Solar UV irradiation in the range of $100-400 \mathrm{~nm}$ accounts for $8 \%$ of the solar wavelength range $(0.115 \mu \mathrm{m}$ up to $50 \mu \mathrm{m})$, so the intensity of UV radiation is only about $8 \%$ of the total solar energy $\left(1,366 \mathrm{~W} / \mathrm{m}^{2}\right)$. In the near UV range of $200-400 \mathrm{~nm}$, a photon's energy is $E_{\mathrm{ph}}>3 \mathrm{eV}$, and increases to $E_{\mathrm{ph}}>5 \mathrm{eV}$ for the vacuum UV range below $200 \mathrm{~nm}$. When UV irradiation is energetic enough, it can break organic bonds such as $\mathrm{C}-\mathrm{C}$ and $\mathrm{C}-\mathrm{O}$ functional groups since a photon's energy at $250 \mathrm{~nm}$ is $480 \mathrm{~kJ} / \mathrm{mol}$, while the strength of C-C and C-O bonds are approximately 420 and $340 \mathrm{~kJ} / \mathrm{mol}$, respectively, or even lower in the neighborhood of aromatic or unsaturated structures [27]. The absorption of highenergy light at these energy levels can lead to bond breakage and the production of free radicals. These free radicals have high chemical reactivity and can result in chemical reactions with gases, propagating chain scission and cross-linking through chain reactions [28]. High-energy particulate radiation is predominantly 
trapped radiation like EL (up to several $\mathrm{MeV}$ ) and $\mathrm{Pr}$ (up to several hundred $\mathrm{MeV}$ ). The primary effects of these particulate radiations on materials are ionization, phonon excitations and atomic displacement, resulting in crosslinking, chain scission or polymerization [29]. The major atmospheric constituent in LEO is atomic oxygen (AO) from photo-induced dissociation of $\mathrm{O}_{2}$ in the upper atmosphere. Its number density is approximately $8 \times 10^{7}$ atoms $\cdot \mathrm{cm}^{-3}$ at $400 \mathrm{~km}$ altitude, and the AO flux orbit is $10^{14} \sim 10^{15}$ atoms $\cdot \mathrm{cm}^{-2} \cdot \mathrm{s}^{-1}$.

Under such harsh environments, direct contact between metallic surfaces would result in high friction and high wear through seizure or even cold welding which could easily inflict fatal damage to the satellites and spacecrafts with no possibility of repair. Protective coatings are of paramount importance because they can prevent moving surfaces from coming into direct contact. Hence, a prerequisite for space applications of DLC as protective coatings is to systematically study the physical and tribological properties under space environments including high vacuum, fluctuating temperatures and irradiation. Enke et al. [16] firstly reported low friction coefficients (0.01-0.02) of DLC films under vacuum as early as 1980 . Soon after, numerous studies were carried out by the Argonne National Laboratory and others to investigate the friction and wear behavior of DLC films and its associated mechanism in high vacuum and in different atmospheres. They focused on the tribology performance of DLC films and pointed out that friction coefficients of less than 0.01 and up to 1 may be achieved with these materials, depending on both composition and testing conditions [30]. In ambient air, friction coefficients change in the range of 0.05 and 0.3 , whereas in inert environments including ultra-high vacuum, dry $\mathrm{N}_{2}$ or dry argon, they can reach either ultra-low values $(<0.01)$ or high values $(>0.5)$. Furthermore, the composition of the DLC film strongly affects its tribological properties. For example, the friction coefficient increases with increasing relative humidity (RH) for a-C:H film in ambient air [31], whereas it decreases with increasing $\mathrm{RH}$ for a-C or ta-C films [32], and friction coefficients of $<0.01$ and as low as 0.001 can be obtained only for a-C:H films under vacuum or inert environment [33-35]. These results confirm that hydrogen is key to the low friction behavior of these films and that the presence of water molecules has an adverse effect on their friction behavior [36, 37]. In 1997, Donnet and Grill [38] showed the existence of a threshold in hydrogen content of DLC films deposited by plasma-enhanced chemical vapor deposition (PECVD) in ultra-high vacuum of $34-40$ at.\% of hydrogen content, which provides high $(>0.5)$ and low $(<0.02)$ friction coefficients in ultra-high vacuum, respectively. Fontaine et al. [39] pointed out that surface rheological properties may be of paramount importance in the achievement of superlow friction with a-C:H films because a film with low hydrogen content and a low viscoplastic exponent under vacuum can achieve superlow friction in ambient hydrogen. Moreover, low or surperlow friction of a-C:H films is always attributed to the formation of a smooth transfer film. Adhesion leads to the loss of superlow friction, probably due to interactions between the $\pi$-orbitals of $\mathrm{sp}^{2}$ carbon atoms on both counterfaces. Hence, to achieve superlow friction, it is necessary to control the composition of the sliding surfaces and the rheology of the transfer film. Both high hydrogen content of the pristine a-C:H film and feeding the a-C:H or transfer film surface with hydrogen are sufficient to avoid adhesive interactions and to modify the interfacial material, and can also induce a "healing" effect on damaged surfaces [40,41]. When DLC films are used as protective coatings for space applications, they have to overcome widely fluctuating temperatures. With the development of deposition and test techniques, it has been confirmed that DLC films retain their excellent mechanical and tribological properties under high or low temperatures [42,43]. Many systems of artificial satellites and spacecrafts are exposed to atomic oxygen, solar radiation, energetic particles, and temperatures which fluctuate from cryogenic (i.e., below $-150{ }^{\circ} \mathrm{C}$ ) to $400{ }^{\circ} \mathrm{C}$ over several decades, so they require solid lubricant coatings which can withstand such extreme conditions. The effects of simulated irradiation on the properties of DLC films have been experimentally evaluated and systematically analyzed with relevance to space environmental effects in LEO. Severe oxidation of DLC and doped-DLC surfaces exposed to $\mathrm{AO}$ has not been detected, which may suggest that these materials are resistant to atomic 
oxygen irradiation [44]. Doped-DLC films (like a-C:H:N) with high radiation resistance have shown that they could be used as coatings for space applications to protect against damage from low-energy particles and UV irradiation because the deposition process of doped-DLC films can result in a multilayer structure with depth gradients of refractive indexes, which assures optimal antireflection and protective effects for space applications $[45,46]$. Indeed, following exposure to synchrotron radiation in the soft X-ray region using Ar cluster and $\mathrm{Ar}^{+}$or $\mathrm{Ni}$ ion irradiation, the surface and physical properties of DLC films were changed by the high energy particles due to ion beam bombardment, resulting in improved hardness and roughness. As such, it actually seems to be advantageous for DLC materials to undergo energetic ion bombardment to increase their hardness and smoothness [47-49].

To summarize, DLC coatings have been successfully employed in many conventional mechanical applications to reduce friction and wear. The effects of typical space environments on their physical and tribological properties have been investigated in detail and have demonstrated that these materials are suitable and promising materials for use as protective coatings or lubricants in space applications.

\subsection{Solid lubricant additives}

Worldwide concerted efforts have been made to develop high-performance lubricating additives to further improve the lubrication efficiency of mechanical systems. Graphene has emerged as a promising environmentally friendly candidate to solve lubrication problems because of its unique thin-layer structure and properties including outstanding thermal conductivity $\left(\sim 5,000 \mathrm{~W} \cdot \mathrm{m}^{-1} \cdot \mathrm{K}^{-1}\right)$, extraordinary carrier mobility (up to $27,000 \mathrm{~cm}^{2} \cdot \mathrm{V}^{-1} \cdot \mathrm{s}^{-1}$ ), a large theoretical specific surface area $\left(2,630 \mathrm{~m}^{2} \cdot \mathrm{g}^{-1}\right)$ and excellent mechanical behaviors (Young's modulus of approximately 1,100 GPa, fracture strength of $125 \mathrm{GPa}$ ) which originates from the atoms of graphene linking together through strong and flexible bonds [50, 51]. Recently, some researchers have focused on the nanomechanical and nanotribological properties of single and few-layer graphene and demonstrated that few-layer graphene can significantly improve friction reducing and anti-wear behaviors in mechanical systems due to its unique thin-layer structure. Graphene holds great promise for tribological applications due to its excellent mechanical strength and easy shear capacity, and is one of the most wear resistant materials ever known [52]. In addition, as an atomically smooth two-dimensional material with low surface energy, graphene could be used as a novel protective coating and substitute traditional solid films to reduce friction and adhesion between various contact surfaces [53].

Carbon nanotubes (CNTs) are a state-of-the-art carbon nanomaterial and hold great promise for a wide range of applications in nanoelectronics, composite fabrication, gas storage, optics and electronic devices due to their extraordinary mechanical strength and electrical and thermal conductivity [54]. They are essentially considered to be rolled-up graphene sheets with hexagonally arranged $\mathrm{sp}^{2}$-hybridized carbon atoms. Intense research activities have made remarkable scientific and technological progress in the development of nanostructured materials. Many researchers have proposed CNTs as an intriguing system for studying friction from nano to micro scales because of their special structure including constrained geometry, inert ultra-smooth surfaces, small intershell distance and exceptional properties including remarkable mechanical strength (Young's modulus of $1.8 \mathrm{TPa}$, bend strength as high as $14.2 \mathrm{GPa}$ ), high elastic modulus, large elastic strain and fracture strain sustaining capability $[55,56]$. Hence CNTs hold great promise for fabricating highperformance composites.

Carbon nanomaterials (graphene and CNTs) are environmentally friendly lubricants, which, in addition to exceptional physical properties, friction reducing and anti-wear abilities, can also undergo self-repair. As such, concerted efforts have been made worldwide to develop carbon nanomaterials as high-performance green lubricants.

\section{Liquid lubricants}

Long-term reliable and accurate operational requirements of machine elements always motivate researchers to explore high-performance lubricants more suitable for space technology. Liquid lubricants have presented some unique advantages for addressing lubrication 
problems such as low friction and wear, low mechanical noise, ease of replenishment, ability to remove wear debris and relative adaptivity to their environment [57]. Choosing an appropriate liquid lubricant for use in space is difficult as in space there is no field of gravity, ultra-low ambient pressure $\left(10^{-13}-10^{-16} \mathrm{Tr}\right)$, high temperature variability $\left(-120\right.$ to $\left.150{ }^{\circ} \mathrm{C}\right)$, and energetic ion irradiation [58]. Therefore, special considerations for liquid lubricants in space include evaporative loss, viscosity-temperature properties and adaption to space environments. In view of the harsh space environment and these special requirements, liquid lubricants with unique properties are being used or tested in space engineering including silicone oils, mineral oils, perfluoropolyethers (PFPE), polyalphaolephines (PAO), multiply-alkylated cyclopentanes (MACs), silahydrocarbons (SiHC) and ionic liquids (ILs) [59]. Silicone oils have been used in the aerospace industry due to their good fluidity and high viscosity index, although their use is limited by their poor extreme pressure capacity and easy migration properties. Mineral oils have been successfully used as a general lubricant for a long time, but one of their major disadvantages is that they can be oxidized rapidly at temperatures above $100{ }^{\circ} \mathrm{C}$ and become extremely viscous or gelatinous at temperatures below $-20^{\circ} \mathrm{C}$. PFPE, which is composed of repeat units of perfluorinated aliphatic oxides, exhibits several excellent properties such as uniform viscosity over a wide temperature range, low surface tension, low vapor pressure, low toxicity, and high oxidative/chemical stability [60]. They are an ideal choice for lubrication of magnetic hard disks and spacecrafts. Their shortcomings are metal catalyzed degradation and limited load-carrying capacity. Other lubricants such as PAOs and polyesters are also used for space lubrication. These synthetic lubricants have extended the useful temperature range of fluid-film lubrication from about $-70{ }^{\circ} \mathrm{C}$ to about $300{ }^{\circ} \mathrm{C}$ [61]. In this paper, our attention will focus on MACs and versatile ILs.

MACs are composed of one cyclopentane ring with two to five alkyl groups substituted on the ring, and are synthesized by reacting dicyclopentadiene with alcohols of various chain lengths [62]. MACs consisting of a di- and tri-substituted (2-octylodecyl) cyclopentane ring possess potential applicability towards aerospace mechanisms and micro electromechanical systems (MEMS) due to their good chemical inertness, excellent viscosity properties, low volatility, low pour points and high thermal stability. Extensive research has demonstrated that MACs possess excellent tribological properties as a lubricant on earth and in space [63-65].

ILs are ionic salts with melting points lower than room temperature, and are composed of a relatively large organic cation and a weakly coordinating inorganic anion [66]. Their physical and chemical properties can be tailored by varying the cation or anion and their combinations. There are millions of possibilities for these pairings, so they have potential versatility as an engineering liquid for demanding applications [67]. ILs have attracted considerable attention in a range of applications due to their distinctive properties. Interest in ILs as lubricants is due to their unique range of properties including negligible vapor pressure, excellent thermal stability, wide temperature range, high electrical conductivity, and miscibility with a range of organic compounds. Therefore, ILs have been investigated as versatile lubricants and lubricant additives for contacts of steel with steel, steel with aluminum, steel with copper and modified surface coating on steel [68-75]. We have also systematically studied the physicochemical properties and tribological performance of alkyl imidazolium ILs greases under simulated space environments and conclude that they have a good anti-irradiation capacity, excellent friction reduction and anti-wear abilities as well as good extreme pressure properties [76].

As technologies such as batteries, electronics, thermal and optical systems, and mechanical systems are significantly improved, the challenges associated with lubrication may limit the exploration of space and our universe. On the one hand, solid lubricants are widely used for tribology problems in high vacuum and variable temperature environments because they do not evaporate under high vacuum and result in relatively small changes in physical and chemical properties in response to large variations in temperature. On the other hand, liquid lubricants have many advantages over solid lubricants in terms of their lifetime, self-healing abilities, and high/low speed operation. Given their respective characteristics, some researchers have conceived and designed synergistic 
lubrication systems consisting of solid films and liquid lubricants, which is most promising for the continuous improvement of space technology.

\section{Carbon-based solid-liquid synergetic lubricating materials}

A report from the National Aeronautics and Space Administration (NASA) states that thus far, no lubricant or coating exists or has been validated to meet the requirements of long-term reliable and accurate operation under space environments. With advances in space technology and ever-increasing demands for mechanical systems, superior lubricating systems must be designed and investigated in detail. Intensive efforts have been made to fabricate carbonbased lubricating films (DLC and its derivatives) by deposition techniques which possess excellent mechanical and physical performance. Given the great advance in solid films and liquid lubricants over the past few decades, solid \& liquid lubricating systems are expected to minimize the individual shortcomings of solid and liquid lubricants through synergistic effects. As such, carbon-based solid-liquid systems were prepared and systematically studied under high vacuum, space-like radiation and highly variable temperature conditions. Here we focus on solid-liquid synergistic lubricating coatings prepared via a combination of diamond-like carbon films and low volatile liquid lubricants to meet environmental requirements and achieve the desired tribological performance for space applications. Figure 2 shows the influencing factors of solid-liquid lubricating systems on tribological performance, and illustrates that the tribological performance of the lubricating systems depends on the whole system, including environment, friction conditions, materials and properties of friction pairs, as well as the intrinsic properties of the solid and liquid lubricants.

DLC films are regarded as a class of potential space lubricating materials because they possess high hardness, low friction and wear properties, excellent corrosion resistance, high elastic modulus and high chemical inertness [77]. However, adhesion and coldwelding between the DLC films and the counterpart often occurs under high vacuum conditions, resulting

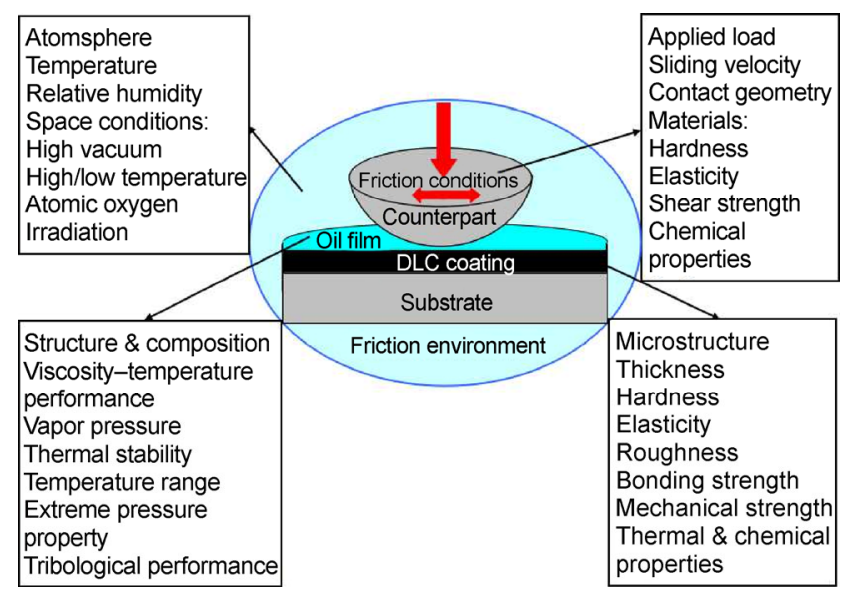

Fig. 2 Influencing factors of solid-liquid lubricating systems on the tribological performance.

in high friction and wear and even lubrication failure, especially for non or low hydrogenated DLC films which exhibit high friction (0.6-1.0) in ultra-high vacuum because the exposed dangling bonds at the surfaces of the film lead to high surface energy and adhesion between contacting interfaces [78]. In contrast, highly hydrogenated DLC films have low friction coefficient values in vacuum conditions, measured in the range of $0.006-0.008$ for steel balls sliding against a-C:H films in vacuum $[79,80]$. Regardless of what kind of DLC film, there are even more difficulties in maintaining long wear life, as low friction coefficient values were only generally maintained for a hundred sliding cycles and then increased to higher values. As such, improving the durability and reliability of DLC films in heavily loaded and high sliding speed conditions under high vacuum environments suitable for space applications has attracted much attention. It is well known that liquid lubricants have advantages including self-healing functionality, long lifetimes, ease of replenishment and the ability to remove wear debris, whilst possessing the disadvantage of limited carrying capacity due to rheological thinning of liquid lubricants under heavy loads. Fortunately, given the advantages of solid lubricating coatings and the unique performance of space liquid lubricants, novel design concepts regarding the combination of solid/liquid lubricating systems have been proposed to improve the lifetime and reliability of lubricating coatings for space related applications. Being such a novel lubricating system, however, only a few studies have reported that oil-lubricated DLC coatings could improve 
the lifetime of key components under atmospheric environments [81, 82]. DLC films have been developed as low-friction and anti-wear protective coatings that are being used successfully in various engineering applications including cylinder heads, mechanical tappets, plunger pistons, piston pins, and bearings. Figure 3 presents the Stribeck curve and corresponding products with DLC films from Wang's group [83]. With the rapid development of DLC films and imperious demands of space tribology, Wang's group has systematically investigated the adaptive abilities and tribological properties of carbon-based solid-liquid synergistic lubricating systems under a simulated space environment.

Initially, Wang et al. [84] selected five kinds of extensively studied liquid lubricants including poly(tetrafluoroethylene oxide-co-difluoromethylene) (Zdol), methyl terminated silicon oil, industrial based oil (PAO 100), MACs and ILs (3-hexyl-1-methylimidazolium hexafluorophosphate) combined with DLC films for fabricating DLC-based solid-liquid composite lubricating coatings. Chemical formulations of the five liquid lubricants are shown in Fig. 4. Table 1 gives the typical physical properties of the liquid lubricants. After comparative research on the tribological properties of these composite lubricating coatings under high vacuum $\left(\sim 10^{-5} \mathrm{~Pa}\right)$, the results demonstrated that the coatings of MACs, IL and Zdol possess excellent friction reducing and wear resistance behaviors in high vacuum because the friction coefficients and wear rates for the contact of DLC with steel were reduced to $0.02-0.05$ and $1-3$ orders of magnitude, respectively, compared with the contact of steel with steel. A composite coating comprised of a TiC/a-C:H film as a supporting layer and MAC as an upper liquid layer was also prepared to study its tribological properties under high vacuum in comparison to a bare TiC/a-C:H film and steel lubricated by MACs only. The results show that the composite coating gave the lowest friction coefficient $(0.08)$ and wear rate $\left(1.5 \times 10^{-8} \mathrm{~mm}^{3} /(\mathrm{N} \cdot \mathrm{m})\right)$, demonstrating that solid/liquid lubricating coatings can provide much lower friction than single solid or liquid lubricants, and can therefore be considered as potential lubricating and protective coatings for moving mechanical systems and tribological components in space [85].

Wang's group further investigated the effects of space irradiation (AO, UV, Pr and EL) on the structure, morphology, composition and tribological performance

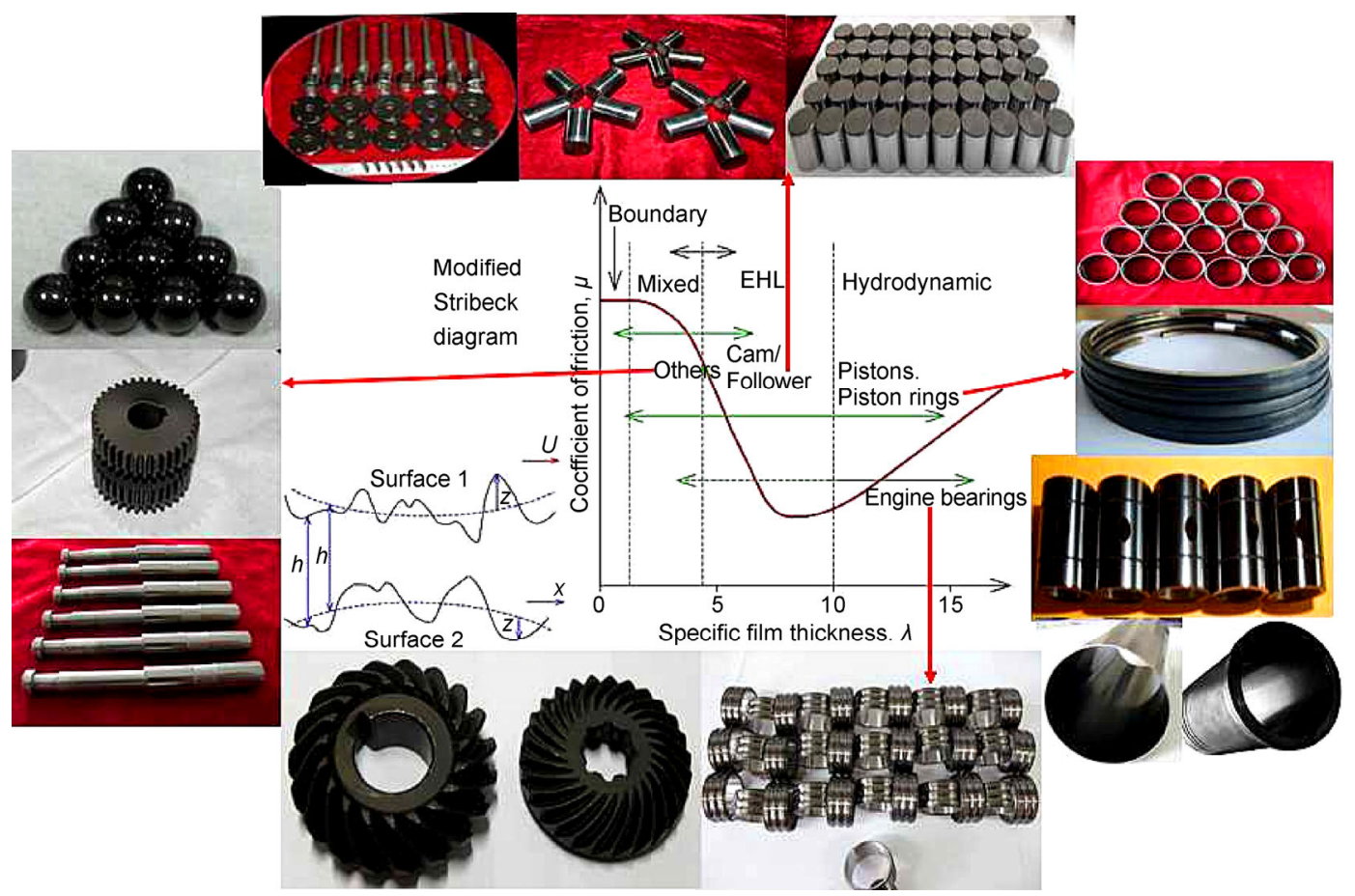

Fig. 3 Schematic of the Stribeck curve (the friction coefficient as a function of the film thickness) and various engineering components with DLC-coated surfaces [83]. 


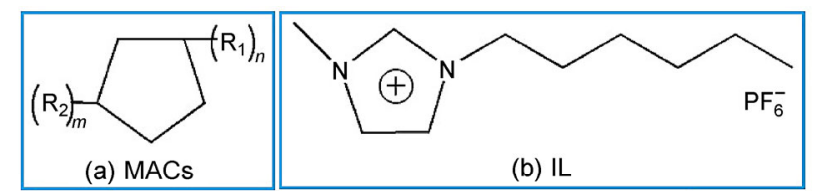

(a) MACs

(b) IL

$\left.\left.\mathrm{HOCH}_{2} \mathrm{CF}_{2} \mathrm{O}-\mathrm{CH}_{2} \mathrm{~F}_{2}-\mathrm{CF}_{2} \mathrm{O}\right]_{m}-\mathrm{CF}_{2} \mathrm{O}\right]_{n}-\mathrm{CF}_{2} \mathrm{CH}_{2} \mathrm{OH}$

(c) Zdol

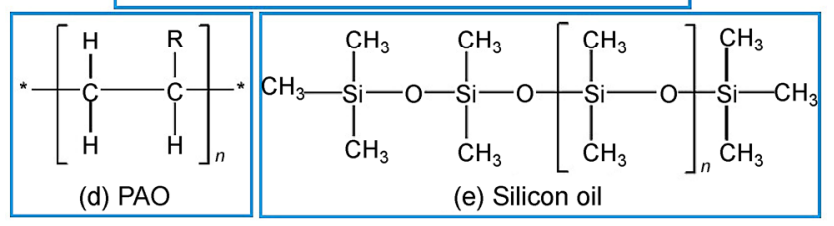

Fig. 4 Chemical formulations of five kinds of lubricants: (a) MACs, $R_{1}$ and $R_{2}$ remarked as different alkyls, two to five alkyl groups substituted on the ring of cyclopentane; (b) IL; (c) Zdol; (d) PAO; (e) silicon oil, $n$ and $m$ are integers.

of DLC films and the composite coatings DLC/IL, DLC/MACs and DLC/Zdol under vacuum condition. The simulated space environment parameters investigate are listed in Table 2 . The results demonstrated that high-energy particles (AO, Pr and EL) changed the structure of the DLC films due to the oxidation of the surface and an increase in the $\mathrm{sp}^{2}$ fraction of the films, which resulted in bond-breakage and crosslinking reactions with the liquid lubricants which could change the physical and chemical properties of the liquid lubricants including their thermal stability, vapor pressure, viscosity-temperature performance, solubility and wettability. Damage due to UV irradiation, however, was minimal. The effects of UV irradiation on the interactions between the lubricant and the substrate surface have been investigated via surface energy, bonded lubricant thickness and lubricant spreading measurements, with the results indicating that UV irradiation decreases the fluidity and polar surface energy of the lubricant films and increases the thickness of lubricant films, suggesting that the interactions between lubricant molecules and the substrate surface were strengthened by UV irradiation $[60,86]$. Therefore, strong enough ultraviolet light could break part of the lubricant's molecular chain, resulting in the bond-breakage and chemical crosslinking reactions, whereas surface adhesion and coverage of lubricants on the substrates are improved by UV irradiation which could eliminate the effects of lubricant damage by UV irradiation on the tribological performance. Figures 5 and 6 show typical XPS C1s spectra and atomic force microscopy (AFM) surface 3D morphology of the DLC films before and after irradiation to search for evidence of severe oxidation and graphitization caused by irradiation. Surprisingly, although space irradiation led to the deterioration and degradation of DLC films and liquid lubricants, the friction coefficients of the composite coatings actually reduced after irradiation (except for $\mathrm{AO}$ ) because, following bombardment with high-energy particles, some activated atoms in the liquid lubricants readily react with metal atoms on the sliding surfaces and generate a tribo-chemical reaction film which

Table 1 Typical physical properties of five kinds of liquid lubricants.

\begin{tabular}{cccccc}
\hline Oils & $\begin{array}{c}\text { Decomposition } \\
\text { Temperature, } T_{\mathrm{d}}\left({ }^{\circ} \mathrm{C}\right)\end{array}$ & $\begin{array}{c}\text { Kinematic viscosity } \\
\left(\mathrm{mm}^{2} / \mathrm{s}\right) 40{ }^{\circ} \mathrm{C}\end{array}$ & $\begin{array}{c}\text { Kinematic viscosity } \\
\left(\mathrm{mm}^{2} / \mathrm{s}\right) 100{ }^{\circ} \mathrm{C}\end{array}$ & $\begin{array}{c}\text { Viscosity index } \\
\left(\mathrm{g} / \mathrm{cm}^{3}\right) 15{ }^{\circ} \mathrm{C}\end{array}$ \\
\hline MACs & 287 & 109 & 15 & 143 & 0.846 \\
IL & 344 & 129 & 14 & 46 & 106 \\
Zdol & 264 & 146 & 100 & 351 & 169 \\
PAO100 & 360 & 1240 & 155 & 446 & 0.857 \\
Silicon oil & 364 & 378 & 462 & 0.982 \\
\hline
\end{tabular}

Table 2 Experimental parameters of stimulated space environment and friction.

\begin{tabular}{cll}
\hline Irradiation & \multicolumn{1}{c}{ Parameters } & Friction condition \\
\hline $\mathrm{AO}$ & $6.5 \times 10^{15} \mathrm{atom} /\left(\mathrm{cm}^{2} \cdot \mathrm{s}\right), 5 \mathrm{eV}, 2 \mathrm{~h}$ & $3 \mathrm{~N}, 500 \mathrm{r} / \mathrm{min}, 1 \mathrm{~h}, 10^{-5} \mathrm{~Pa}$ \\
$\mathrm{EL}$ & $2.5 \times 10^{14} \mathrm{~cm}^{-2} \cdot \mathrm{s}^{-1}, 25 \mathrm{KV}, 5 \mathrm{~min}$ & $3 \mathrm{~N}, 500 \mathrm{r} / \mathrm{min}, 1 \mathrm{~h}, 10^{-5} \mathrm{~Pa}$ \\
$\mathrm{Pr}$ & $2.5 \times 10^{14} \mathrm{~cm}^{-2} \cdot \mathrm{s}^{-1}, 25 \mathrm{KV}, 5 \mathrm{~min}$ & $3 \mathrm{~N}, 500 \mathrm{r} / \mathrm{min}, 1 \mathrm{~h}, 10^{-5} \mathrm{~Pa}$ \\
$\mathrm{UV}$ & $800 \mathrm{~W} / \mathrm{m}^{2}, 115-400 \mathrm{~nm}, 2 \mathrm{~h}$ & $3 \mathrm{~N}, 500 \mathrm{r} / \mathrm{min}, 1 \mathrm{~h}, 10^{-5} \mathrm{~Pa}$ \\
HT/LT & between $-100{ }^{\circ} \mathrm{C}$ and $150{ }^{\circ} \mathrm{C}$ & $3 \mathrm{~N}, 500 \mathrm{r} / \mathrm{min}, 1 \mathrm{~h}, 10^{-5} \mathrm{~Pa}$ \\
\hline
\end{tabular}



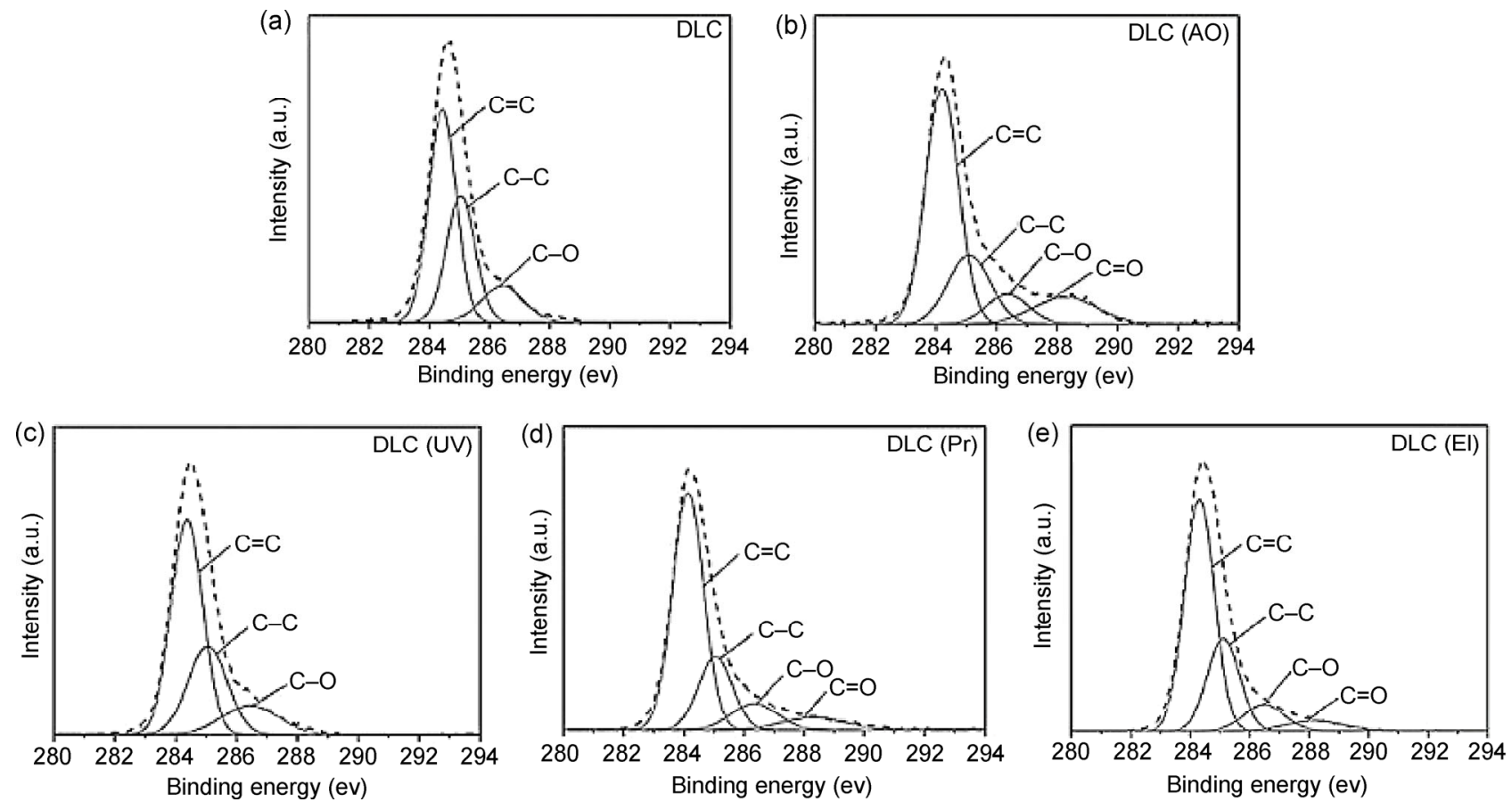

Fig. 5 Typical XPS C1s spectra of the DLC films before and after irradiation: (a) DLC sample, (b) DLC by AO irradiation, (c) DLC by UV irradiation, (d) DLC by proton irradiation, and (e) DLC by electron irradiation [88].

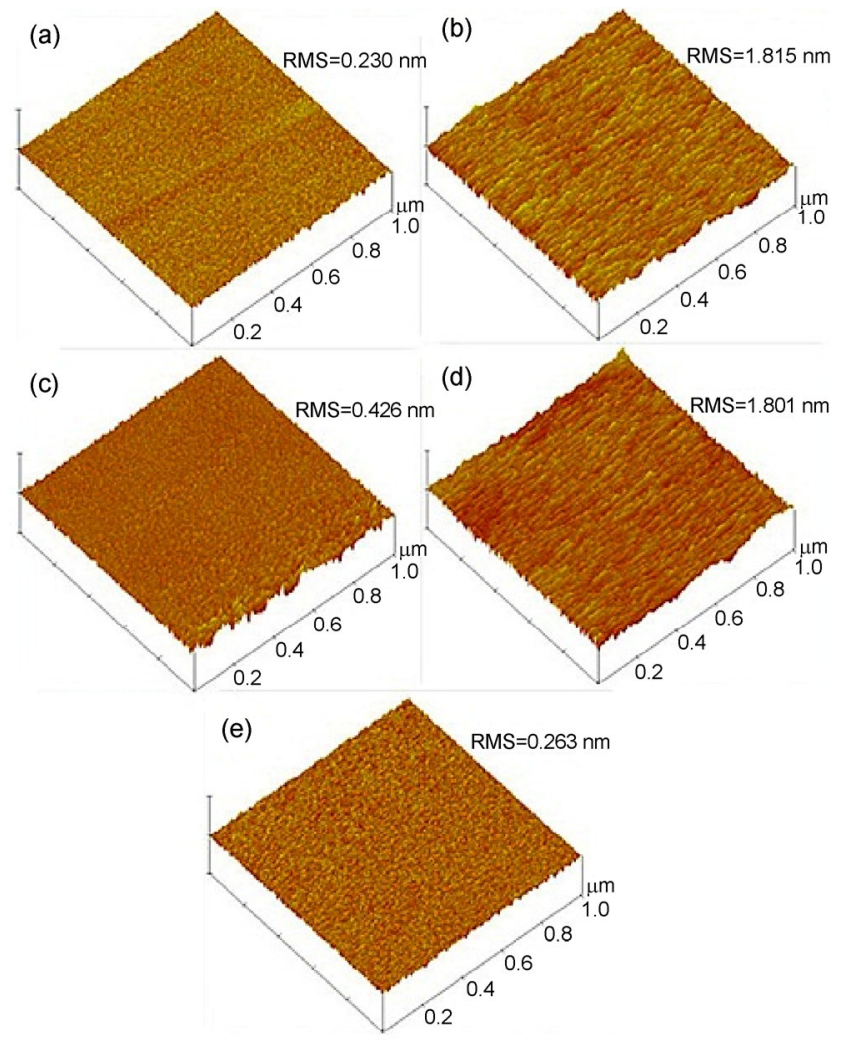

Fig. 6 AFM surface 3D morphology of DLC films before and after irradiation: (a) DLC sample, (b) DLC by AO irradiation, (c) DLC by UV irradiation, (d) DLC by proton irradiation, and (e) DLC by electron irradiation [87]. further improves friction reduction performance, whereas the wear rates after irradiation were larger than that before irradiation due to a weakening in wear resistance ability from irradiation damage $[87,88]$. Figure 7 provides friction curves for DLC/IL composite coatings before and after irradiation. The DLC/IL, DLC/MACs and DLC/Zdol composite coatings have good tribological properties, however the DLC/IL composite provides the lowest friction coefficient at high temperature $\left(100^{\circ} \mathrm{C}\right)$ under high vacuum because high temperature improves the mobility, wettability and self-repairing capacity of IL and induces a favorable tribo-chemical reaction during the friction process in addition to the slight surface graphitization of the DLC film [89]. Figure 8 presents the schematic diagram for the possible lubrication mechanism for the DLC-based solid-liquid composite systems. The DLC film provides a hard supporting layer, high carrying capacity and friction-reducing ability, whilst the liquid lubricating film in the upper layer improves the tribological performance due to the formation of a tribo-film that prevents the rubbing surfaces from coming into direct contact and significantly enhances the wear resistance ability. 
(a)
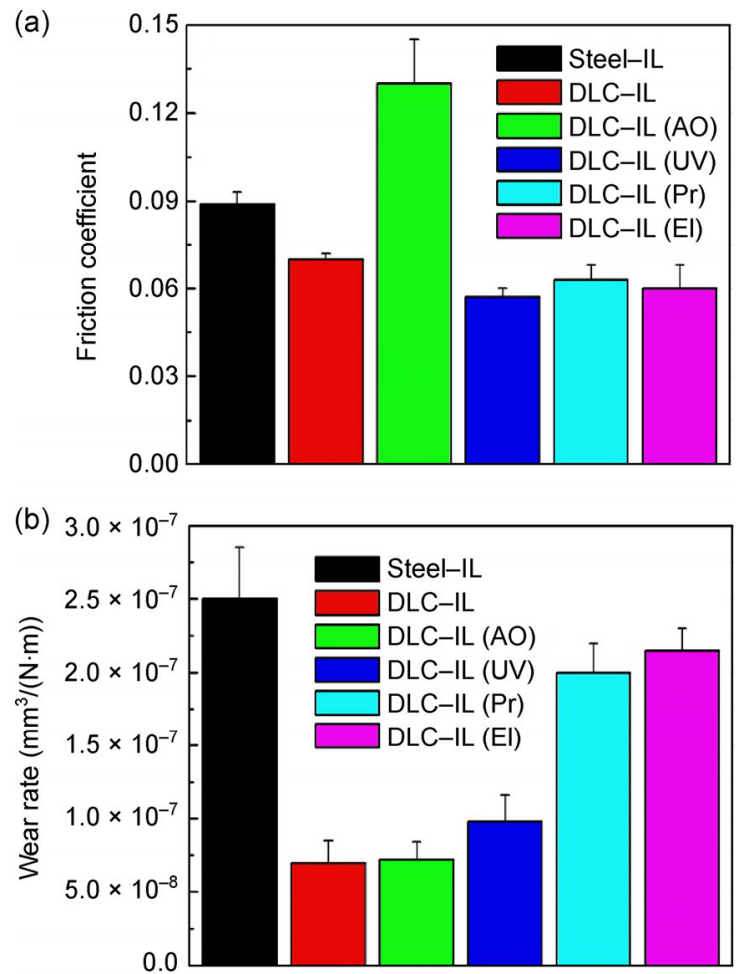

Fig. 7 Average friction coefficient values (a) and wear rate (b) of the DLC/IL solid-liquid composite coatings before and after irradiation in comparison with steel/IL at applied load of $3 \mathrm{~N}$ and under high vacuum condition (around $10^{-5} \mathrm{~Pa}$ ) for $60 \mathrm{~min}$.

In order to further improve the tribological performance of the composite coatings in a space environment, Wang's group has used carbon nanomaterials (graphene and carbon nanotube) as ionic liquid lubricant additives due to their high mechanical strength, high thermal conductivity and excellent thermal stability, which make them more suitable candidates than traditional additives. Graphene- and CNTs-based additives for base oil have already been studied in detail [90-93], with the results indicating that they could significantly improve the lubricant's tribological properties and lifetime as they are heat resistant, durable and self-lubricating. Wang's group firstly fabricated composite lubricating systems composed of IL with graphene and CNTs as lubricant additives and DLC films (DLC/IL/graphene and DLC/IL/graphene+CNTs), and evaluated their potential for space tribology. The results indicated that the DLC/IL/graphene system with $0.075 \mathrm{mg} / \mathrm{mL}$ graphene provided the lowest friction and wear under high vacuum and irradiation environments due to the formation of fluorinated oil-containing carbon-rich tribo-films between the friction pairs. The results for the DLC/IL/graphene+CNTs system illustrate that CNTs were more effective in reducing friction at low applied loads, whereas graphene was more effective at high applied loads. These differences are mainly due to microstructural variations between CNTs and graphene during the friction process as well as the transfer of graphene and CNTs [94,95]. Figure 9 presents the schematic diagram for the possible lubrication mechanism for the DLC/IL/graphene+CNTs system. Graphene nanosheets easily stack and become thicker after the friction test under low applied loads,

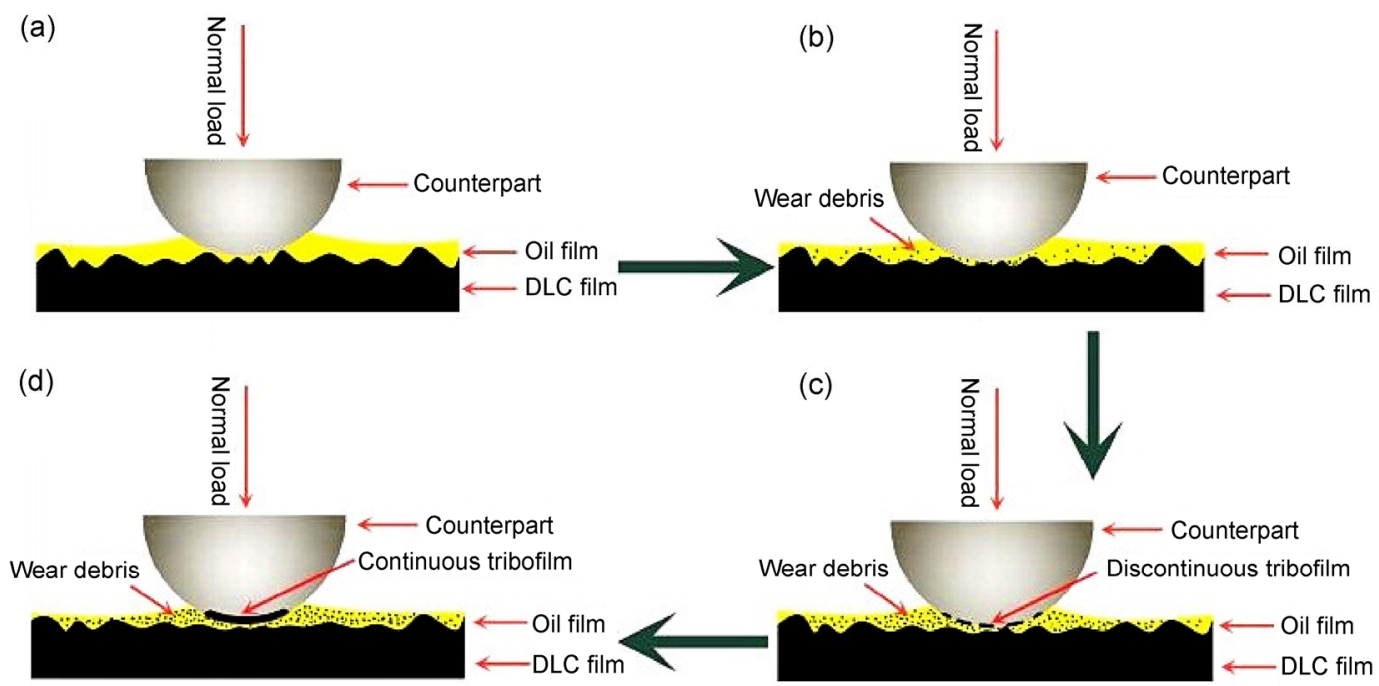

Fig. 8 Schematic diagram for the possible lubrication mechanism for the DLC-based solid-liquid composite coatings (DLC/liquid lubricants) [85]. 

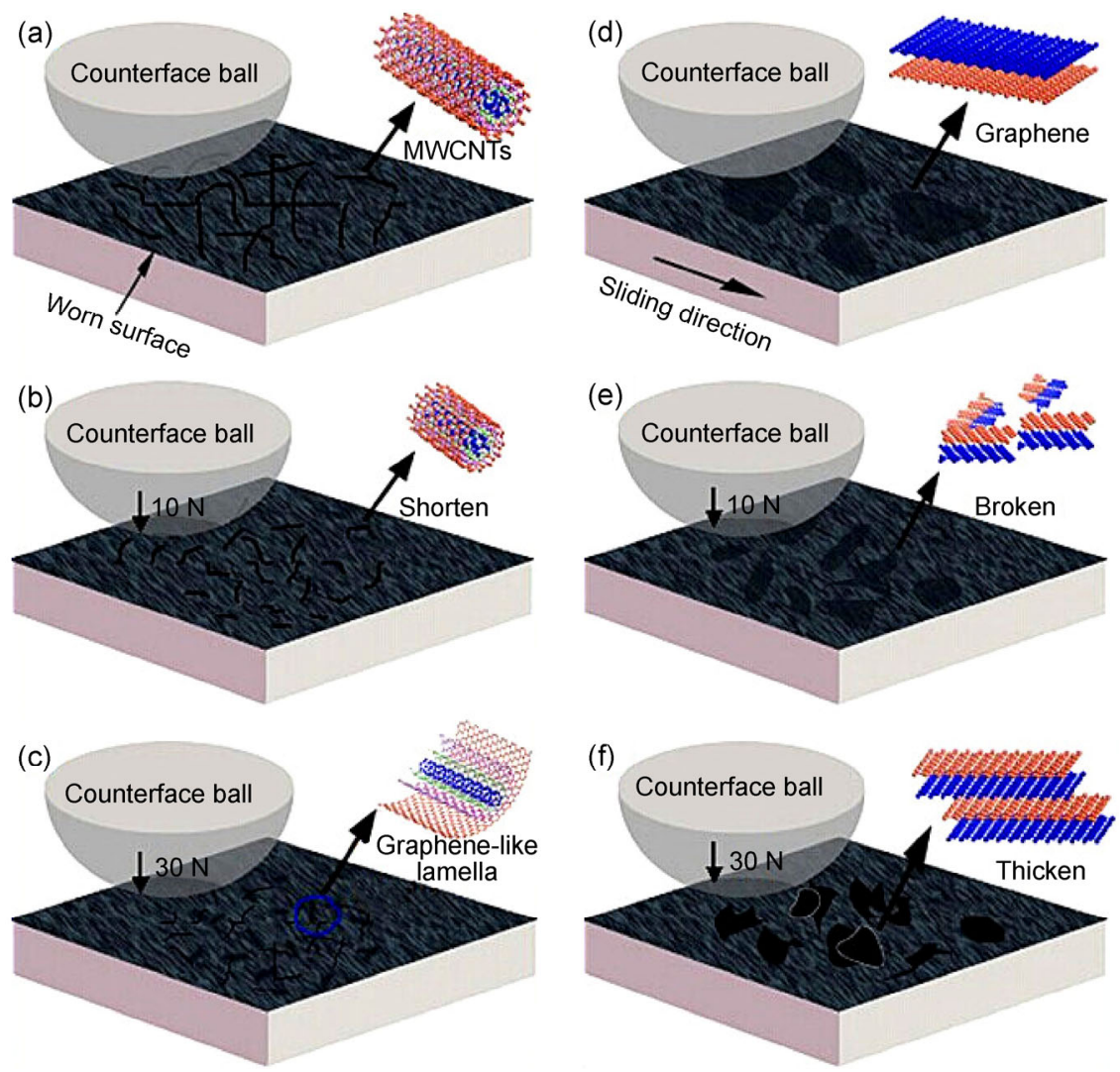

Fig. 9 Schematic diagram for the possible lubrication mechanism for the carbon-based solid-liquid composite coatings (DLC/IL/ graphene+CNTs) [95].

and formed the sandwich structure of the graphene sheets crosslinked by ILs after prolonged friction testing at high vacuum, which could also be beneficial for sliding between graphene layers. Multiwall carbon nanotubes (MWCNTs) also play a significant role in improving the tribological properties because of the ease of rolling and unwrapping MWCNTs and graphene-like fragments due to friction can form a physical protective film which prevents the rubbing surfaces from coming into direct contact and significantly enhances wear resistance.

To summarize, DLC-based solid-liquid synergy lubricating systems composed of DLC films as a supporting layer and liquid lubricants as upper lubricating layer show excellent friction-reducing and anti-wear performance because the solid-liquid synergy lubrication not only maintains the yield strength determined by the hardness of the DLC film, but also improves the shear strength due to the soft film of liquid lubricant. As such, these low viscosity lubricants with good mobility can maintain continuous and effective lubrication at the friction interface, whilst the carbon-based films can contend with high bearing capacities due to their hardness. Under simulated space environments, the primary effect of high-energy $\mathrm{Pr}$ and EL irradiation on the lubricating coatings is ionization, phonon excitation and atom displacement which can result in crosslinking, chain scission or polymerization of the upper layer. The strong oxidising nature of atomic oxygen could also directly react with materials and lead to erosion and degradation. UV irradiation strengthens the interactions between the lubricant and the substrate surface that could negate the effects of UV irradiation of lubricants towards tribological performance. High-energy particles can change the structure of DLC films due to oxidation of the surface, increasing the $\mathrm{sp}^{2}$ fraction in films and resulting in bond-breakage and crosslinking reactions of liquid lubricants, whereas solid/liquid composite coatings can weaken the damage of space irradiation and prolong the lifetime of the lubricating coatings. DLC/IL/graphene and DLC/IL/graphene+CNTs systems 
could further improve the reduction in friction and increase wear resistance and anti-irradiation properties under simulated space environments because fluorinated oil-containing carbon-rich tribo-films form on the friction pairs between graphene or graphene/CNTs and IL which significantly enhances the friction reducing capacity and wear resistance in high vacuum and irradiated environments.

\section{Conclusion and outlook}

Since carbon-based solid films were firstly reported over 60 years ago, increasing research on deposition techniques, their physicochemcial properties and applications have been carried out and have made great progress on their preparation and performance. Today DLC films have been indispensable for diesel injection systems and have established a large number of applications in the atmospheric environment. Moreover, DLC films as hard protective coatings hold great promise for space tribology because they can minimize abrasion, shear, and adhesive phenomena. To optimize DLC coatings for specific applications under the harsh space environment, DLC-based solidliquid synergy lubricating systems have been fabricated and systematically investigated. These systems provide excellent tribological properties and good adaptive abilities to the space environment, which is important for the long-term operation of reliable and accurate moving mechanisms in space. Hence DLC-based solid-liquid synergy lubricating systems offer great potential for the development of space applications.

Future development and trends in DLC and DLCbased solid-liquid composite coatings should take into consideration the following:

(a) Development and optimization of reliable homogeneous deposition processes for DLC films to reduce the costs and expand their industrial application, for example, for the coating of three-dimensional parts.

(b) Continuous improvement of the adhesion between films and substrates to provide better tribological performance and long service life.

(c) More research on the performance of films under various friction conditions and environments to understand their relationship and friction mechanism, thereby contributing to better design and selection of appropriate lubricating systems. (d) Optimization of carbon-based solid-liquid composite coatings taking into account practical operation under various friction conditions to obtain improved friction reducing and anti-wear performance.

\section{Acknowledgments}

The authors gratefully acknowledge the financial support by the National Natural Science Foundation of China (Nos. 21373249 and 11172300). The authors also very ackowledge Xiufang Liu and Lili Zhang for providing the relevant information.

Open Access: This article is distributed under the terms of the Creative Commons Attribution License which permits any use, distribution, and reproduction in any medium, provided the original author(s) and source are credited.

\section{References}

[1] Philip C H M. Oil-soluble Mo-S compounds as lubricant additives. Wear 100: 281-300 (1984)

[2] Papoport L, Leshchinsky V, Lapsker I, Volovik Y, Nepomnyashchy O, Lvovsky M, Popovitz-Biro R, Feldman Y, Tenne R. Tribological properties of $\mathrm{WS}_{2}$ nanoparticles under mixed lubrication. Wear 255: 785-793 (2003)

[3] Hu Z, Lai R, Lou F, Wang L, Chen Z, Chen G, Dong J. Preparation and tribological properties of nanometer magnesium borate as lubricating oil additive. Wear 252: 370-374 (2002)

[4] Dong J, Hu Z. A study of the anti-wear and friction-reducing properties of the lubricant additive, nanometer zinc borate. Tribol Int 31: 219-223 (1998)

[5] Zhou J, Yang J, Zhang Z, Liu W, Xue Q. Study on the structure and tribological properties of surface-modified $\mathrm{Cu}$ nanoparticles. Mater Res Bull 34: 1361-1367 (1999)

[6] Fan X, Wang L, Xia Y. Oil-soluble lithium salts as novel lubricant additives towards improving conductivity and tribological performance of bentone grease. $\mathrm{Lubr}$ Sci, DOI: 10.1002/1s.1286 (2014)

[7] Lettington A H. Applications of diamond-like carbon thin films. Carbon 36: 555-560 (1998)

[8] Cui L C, Lu Z B, Wang L P. Probing the low-friction mechanism of diamond-like carbon by varying of sliding velocity and vacuum pressure. Carbon 66: 259-266 (2014)

[9] Bewilogua K, Hofmann D. History of diamond-like carbon films-From first experiments to worldwide applications. Surf Coat Tech 242: 214-225 (2014) 
[10] Reinke P, Jacob W, Möller W. Influence of the ion energy on the growth and structure of thin hydrocarbon films. J Appl Phys 74: 1354-1361 (1993)

[11] Jacob W, Möller W. On the structure of thin hydrocarbon films. Appl Phys Lett 63: 1771-1773 (1993)

[12] Robertson J. Properties of diamond like carbon. Surf Coat Tech 50: 185-203 (1992)

[13] Hainsworth S V, Uhure N J. Diamond like carbon coatings for tribology: Production techniques, characterization methods and applications. Int Mater Rev 52: 153-174 (2007)

[14] Donnet C, Erdemir A. Tribology of Diamond-Like Carbon Films: Fundamentals and Applications. Springer, 2007.

[15] King F K. Datapoint thin film media. IEEE Trans Magn 17: 1376-1378 (1981)

[16] Enke K, Dimigen H, Hubsch H. Frictional properties of diamond-like carbon layers. Appl Phys Lett 36: 291-292 (1980)

[17] Grill A. Tribology of diamond-like carbon and related materials: An updated review. Surf Coat Tech 94-95: 507-513 (1997)

[18] Donnet C, Grill A. Friction control of diamond-like carbon coatings. Surf Coat Tech 94-95: 456-462 (1997)

[19] Donnet C. Recent progress on the tribology of doped diamondlike and carbon alloy coatings: A review. Surf Coat Tech 100-101: 180-186 (1998)

[20] Grill A. Review of the tribology of diamond-like carbon. Wear 168: 143-153 (1993)

[21] Holmberg K, Ronkainen H, Matthews A. Tribology of thin coatings. Ceram Int 26: 787-795 (2000)

[22] Hauert R. An overview on the tribological behavior of diamond-like carbon in technical and medical applications. Tribol Int 37: 991-1003 (2004)

[23] Grill A. Diamond-like carbon coatings as biocompatible materials-An overview. Diam Relat Mater 12: 166-170 (2003)

[24] Kalin M, Velkavrh I, Vižintin, Ožbolt L. Review of boundary lubrication mechanisms of DLC coatings used in mechanical applications. Meccanica 43: 623-637 (2008)

[25] Donnet C. Advanced solid lubricant coatings for high vacuum environments. Surf Coat Tech 80: 151-156 (1996)

[26] Takano A. Tribology-related space mechanism anomalies and the newly constructed high-vacuum mechanism test facilities in NASDA. Tribol Int 32: 661-671 (1999)

[27] Grossman E, Gouzman I. Space environment effects on polymers in low earth orbit. Nucl Instrum Methods Phy Res Sect B 208: 48-57 (2003)

[28] Fortin J B, Lu T M. Ultraviolet radiation induced degradation of poly-para-xylylene (parylene) thin films. Thin Solid Films 397: 223-228 (2001)

[29] Tagawa M, Muromoto M, Hachiue S, Yokota K, Ohmae N, Matsumoto K, Suzuki M. Hyperthermal atomic oxygen interaction with $\mathrm{MoS}_{2}$ lubricants and relevance to space environmental effects in low earth orbit-effects on friction coefficient and wear-life. Tribol Lett 18: 437-443 (2005)

[30] Andersson J, Erck R A, Erdemir A. Friction of diamondlike carbon films in different atmospheres. Wear 254: 1070 1075 (2003)

[31] Donnet C, Le Mogne T, Ponsonnet L, Belin M, Grill A, Patel V, Jahnes C. The respective role of oxygen and water vapor on the tribology of hydrogenated diamond-like carbon coatings. Tribol Lett 4: 259-265 (1998)

[32] Voevodin A A, Phelps A W, Zabinsky J S, Donley M S. Friction induced phase transformation of pulsed laser deposited diamond-like carbon. Diamond Relat Mater 5: 1264-1269 (1996)

[33] Gao F, Erdemir A, Tysoe W T. The tribological properties of low-friction hydrogenated diamond-like carbon measured in ultrahigh vacuum. Tribol Lett 20: 221-227 (2005)

[34] Erdemir A, Eryilmaz O L, Fenske G. Synthesis of diamondlike carbon films with superlow friction and wear properties. $S c i$ Technol A 18: 1987-1992 (2000)

[35] Fontaine J. Towards the use of diamond-like carbon solid lubricant coatings in vacuum and space environments. Proc IMechE J-J Eng Tribol 222: 1015-1029 (2008)

[36] Donnet C, Belin M, Auge J C, Martin J M, Grill A, Patel V. Tribochemistry of diamond-like carbon coatings in various environments. Surf Coat Technol 68: 626-631 (1994)

[37] Liu Y, Erdemir A, Meletis E I. A study of the wear mechanism of diamond-like carbon films. Surf Coat Technol 82: 48-56 (1996)

[38] Donnet C, Grill A. Friction control of diamond-like carbon coatings. Surf Coat Tech 94: 456-462 (1997)

[39] Fontaine J, Loubet J L, Mogne T L, Grill A. Superlow friction of diamond-like carbon films: A relation to viscoplastic properties. Tribol Lett 17: 709-714 (2004)

[40] Fontaine J, Le Mogne T, Loubet J L, Belin M. Achieving superlow friction with hydrogenated amorphous carbon: some key requirements. Thin Solid Films 482: 99-108 (2005)

[41] Fontaine J, Belin M, Le Mogne T, Grill A. How to restore superlow friction of DLC: the healing effect of hydrogen gas. Tribo Int 37: 869-877 (2004)

[42] Hanzelka P, Kralik T, Maskova A, Musilova V, Vyskocil J. Thermal radiative properties of a DLC coatings. Cryogenics 48: 455-457 (2008)

[43] Wang J J, Pu J B, Zhang G A, Wang L P. Architecture of superthick diamond-like carbon films with excellent high temperature wear resistance. Tribol Int 81: 129-138 (2015)

[44] Marciano F R, Bonetti L F, Pessoa R S, Marcuzzo J S, Massi M, Santos L V, Trava-Airoldi V J. The improvement of DLC film lifetime using silver nanoparticles for use on 
space devices. Diam Relat Mater 17: 1674-1679 (2008)

[45] VG Litovchenko, NI Klyui. Solar cells based on DLC film-Si structures for space application. Sol Energ Mater Sol Cells 68: 55-70 (2001)

[46] Ji L, Li H X, Zhao F, Quan W L, Chen J M, Zhou H D. Influences of ultraviolet irradiation on structure and tribological properties of diamond-like carbon films. Appl Surf Sci 255: 8409-8413 (2009)

[47] Imai R, Fujimoto A, Okada M, Matsui S, Yokogawa T, Miura E, Yamasaki T, Suzuki T, Kanda K. Soft X-ray irradiation effect on the surface and material properties of highly hydrogenated diamond-like carbon thin films. Diam Relat Mater 44: 8-10 (2014)

[48] Kitagawa T, Miyauchi K, Kanda K, Matsui S, Toyoda N, Tsubakino H, Matsuo J, Yamada I. Difference of irradiation effects between Ar cluster ion and $\mathrm{Ar}^{+}$for DLC film formation. In AIP Conference Proceedings, IOP Institute of Physics Publishing LTD, 2003: 755-758.

[49] Kumar V V S. Study of $130 \mathrm{Mev}$ Ni ion irradiation induced surface modification of DLC films grown by microwave plasma CVD. J Appl Phys 3: 1-5 (2013)

[50] Geim A K, Novoselov K S. The rise of graphene. Nat Mater 6: 183-191 (2007)

[51] Chen Y, Zhang B, Liu G, Zhuang X D, Kang E-T. Graphene and its derivatives: switching ON and OFF. Chem Soc Rev 41: 4688-4707 (2012)

[52] Berman D, Erdemir A, Sumant A V. Few layer graphene to reduce wear and friction on sliding steel surfaces. Carbon 54: 454-459 (2013)

[53] Berman D, Erdemir A, Sumant A V. Graphene: A new emerging lubricant. Materi Today 17: 31-42 (2014)

[54] Bourlon B, Glattli D C, Miko C, Forró L, Bachtold A. Carbon nanotube based bearing for rotational motions. Nano Lett 4 : 709-712 (2004)

[55] Kis A, Jensen K, Aloni S, Mickelson W, Zettl A. Interlayer forces and ultralow sliding friction in multiwalled carbon nanotubes. Phy Rev Lett 97: 025501 (2006)

[56] Chen W X, Tu J P, Wang L Y, Gan H Y, Xu Z D, Zhang X B. Tribological application of carbon nanotubes in a metal-based composite coating and composites. Carbon 41: 215-222 (2003)

[57] Zaretsky E V. Liquid Lubrication in Space. Tribol Int 23: 75-93 (1990)

[58] Barth J L, Stassinopoulos E G. Space, atmospheric, and terrestrial radiation environments. IEEE Trans Nucl Sci 50: 466-482 (2003)

[59] Katdoǹski T, Wojdyna P P. Liquid lubricants for space engineering and methods for their testing. $J$ KONES Powertrain Transp 18: 163-184 (2011)
[60] Saperstein D D, Lin L J. Improved surface adhesion and coverage of perfluoropolyether lubricants following far-UV irradiation. Langmuir 6: 1522-1524 (1990)

[61] Zhou F, Liang Y, Liu W. Ionic liquid lubricants: Designed chemistry for engineering applications. Chem Soc Rev 38: 2590-2599 (2009)

[62] Song Z H, Liang Y M, Fan M J, Zhou F. Liu W M. Lithium-based ionic liquids as novel lubricant additives for multiply alkylated cyclopentanes (MACs). Friction 1: 222-231 (2013)

[63] Ma J Q, Pang C J, Mo Y F, Bai MW. Preparation and tribological properties of multiply-alkylated cyclopentane (MAC)-octadecyltrichlorosilane (OTS) double-layer film on silicon. Wear 263: 1000-1007 (2007)

[64] Wang Y, Wang L P, Mo Y F, Xue Q J. Fabrication and tribological behavior of patterned multiply-alkylated cyclopentanes (MACs)-octadecyltrichlorosilane (OTS) dualcomponent film by a soft lithographic approach. Tribol Lett 41: 163-170 (2011)

[65] Jones W R, Poslowski A K, Shogrin B A, Herrera-Fierro P, Jansen M J. Evaluation of several space lubricants using a vacuum four-ball tribometer. Tribol Trans 42: 317-323 (1999)

[66] Bonhöte P, Dias A-P, Papageorgiou N, Kalyanasundaram K, Grätzel M. Hydrophobic, highly conductive ambienttemperature molten salts. Inorg Chem 35: 1168-1178 (1996)

[67] Freire M G, Carvalho P J, Fernandes A M, Marrucho I M, Queimada A J, Coutinho J A P. Surface tension of imidazolium based ILs: Anion, cation, temperature and water effect. $J$ Colloid Interface Sci 314: 621-630 (2007)

[68] Ye C F, Liu W M, Chen Y, Yu L. Room-temperature ILs: A novel versatile lubricant. Chem Commun 21: 2244-2245 (2001)

[69] Yao M H, Fan M J, Liang Y M, Zhou F, Xia Y Q. Imidazolium hexafluorophospate ILs as high temperature lubricants for steel-steel contacts. Wear 268: 67-71 (2010)

[70] Mu Z G, Zhou F, Zhang S X, Liang Y M, Liu W M. Effect of the functional groups in ionic liquid molecules on the friction and wear behavior of aluminum alloy in lubricated aluminum-on-steel contact. Tribol Int 38: 725-731 (2005)

[71] Jimenez A E, Bermudez M D. Imidazolium ILs as additives of the synthetic ester propylene glycol dioleate in aluminiumsteel lubrication. Wear 265: 787-798 (2008)

[72] Fan X Q, Xia Y Q, Wang L P, Pu J B, Chen T D, Zhang H B. Study of the conductivity and tribological performance of ionic liquid and lithium greases. Tribol Lett 53: 281-291 (2014)

[73] Xia Y Q, Sasaki S, Murakami T, Nakano M, Shi L, Wang H $\mathrm{Z}$. Ionic liquid lubrication of electrodeposited nickel- $-\mathrm{Si}_{3} \mathrm{~N}_{4}$ composite coatings. Wear 262: 765-771 (2007) 
[74] Feng X, Xia Y Q. Tribological properties of Ti-doped DLC coatings under ILs lubricated conditions. Appl Surf Sci 258: 2433-2438 (2012)

[75] Wang Z Y, Xia Y Q, Liu Z L. Conductive lubricating grease synthesized using the ionic liquid. Tribol Lett 46: 33-42 (2012)

[76] Fan X Q, Wang L P. Highly conductive ionic liquids toward high-performance space-lubricating greases. ACS Appl Mater Interfaces 6: 14660-14671 (2014)

[77] Donnet C, Erdemir A. Solid lubricant coatings: Recent developments and future trends. Tribol Lett 17: 389-397 (2004)

[78] Gardos M N. Surface chemistry-controlled tribological behavior of silicon and diamond. Tribol Lett 2: 173-187 (1996)

[79] Donnet C, Belin M, Auge J C, Martin J M, Grill A, Patel V. Tribochemistry of diamond-like carbon coatings in various environments. Surf Coat Tech 68-69: 626-631 (1994)

[80] Kano M, Martin J M, Yoshida K, De Barros Bouchet MI. Super-low friction of ta-C coating in presence of oleic acid. Friction 2: 156-163 (2014)

[81] Kalin M, Vižintin J. The tribological performance of DLCcoated gears lubricated with biodegradable oil in various pinion/gear materials combinations, Wear 259: 1270-1280 (2005)

[82] Podgornik B, Sedlaček M, Vižintin J. Compatibility of DLC coatings with formulated oils. Tribol Int 41: 564-570 (2008)

[83] Wang J J, Pu J B, Zhang G A, Wang L P. Interface architecture for superthick carbon-based films toward low internal stress and ultrahigh load-bearing capacity. ACS Appl Mater Interfaces 5: 5015-5024 (2013)

[84] Liu X F, Wang L P, Xue Q J. DLC-based solid-liquid synergetic lubricating coatings for improving tribological behavior of boundary lubricated surfaces under high vacuum condition. Wear 271: 889-898 (2011)

[85] Liu X F, Wang L P, Xue Q J. A novel carbon-based solidliquid duplex lubricating coating with super-high tribological performance for space applications. Surf Coat Tech 205: 2738-2746 (2011)

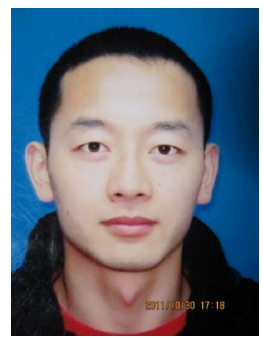

Xiaoqiang FAN. He is currently a PhD student at Lanzhou Institute of Chemical Physics, Chinese Academy of Sciences. He received his Bachelor degree in 2011 from Qingdao University of Science \& Technology.
[86] Zhang H, Mitsuya Y, Imamura M, Fukuoka N, Fukuzawa K. Effect of ultraviolet irradiation on the interactions between perfluoropolyether lubricant and magnetic disk surfaces. Tribol Lett 20: 191-199 (2005)

[87] Liu X F, Wang L P, Xue Q J. High vacuum tribological performance of DLC-based solid-liquid lubricating coatings: Influence of atomic oxygen and ultraviolet irradiation. Tribol Int 60: 36-44 (2013)

[88] Liu X F, Wang L P, Pu J B, Xue Q J. Surface composition variation and high-vacuum performance of DLC/ILs solidliquid lubricating coatings: Influence of space irradiation. Appl Surf Sci 258: 8289-8297 (2012)

[89] Wang L P, Liu X F. Tribological behavior of DLC/IL solidliquid lubricating coatings in a high-vacuum condition with alternating high and low temperatures. Wear 304: 13-19 (2013)

[90] Berman D, Deshmukh S A, Sankaranarayanan S K R S, Erdemir A, Sumant A V. Extraordinary macroscale wear resistance of one atom thick graphene layer. Adv Funct Mater 24: 6640-6646 (2014)

[91] Fan X Q, Xia Y Q, Wang L P, Li W. Multi-layer graphene as a lubricating additive in bentone grease. Tribol Lett $\mathbf{5 5}$ : 455-464 (2014)

[92] Chen C S, Chen X H, Xu L S, Yang Z, Li W H. Modification of multi-walled carbon nanotubes with fatty acid and their tribological properties as lubricant additive. Carbon 43: 1660-1666 (2005)

[93] Peng Y T, Hu Y Z, Wang H. Tribological behaviors of surfactant-functionalized carbon nanotubes as lubricant additive in water. Tribol Lett 25: 247-253 (2007)

[94] Liu X F, Wang L P, Pu J B, Xue Q J. Novel DLC/ionic liquid/graphene nanocomposite coatings towards high-vacuum related space applications. J Mater Chem A 1: 3797-3809 (2013)

[95] Zhang L L, Pu J B, Wang L P, Xue Q J. Frictional dependence of graphene and carbon nanotube in diamondlike carbon/ionic liquids hybrid films in vacuum. Carbon $\mathbf{8 0}$ 734-745 (2014)

His research interests are focused on preparation and tribological property of conductive lubricating greases and functionalized carbon nano-materials as lubricant additives. He has published several papers about graphene-based lubricating materials. 


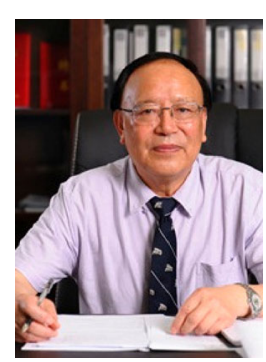

Qunji XUE. Professor, received his Bachelor degree from Shandong University in 1965, and got his master degree from Lanzhou Institute of Chemical Physics in 1967. Prof. Qunji Xue is one of the major academic leaders in materials chemistry and special lubricating

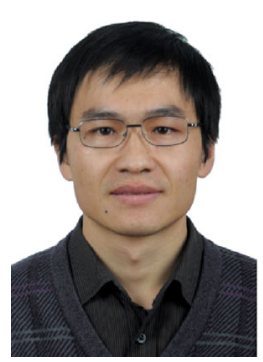

Liping Wang. Professor, got his PhD degree from Lanzhou Institute of Chemical Physics in 2007. He is a full professor in Lanzhou Institute of Chemical Physics, CAS, Group leader of Low-dimensional Materials Tribology, Deputy director of State Key Laboratory of Solid Lubrication. material field and is an Academician of the Chinese Academy of Engineering. He has published over 500 journal papers, 3 books, authorized over 30 patents and gained a number of national scientific awards. He gained "tribology highest achievement award of China" in 2009 and gained the international tribology highest award "Tribology Gold Medal" in 2011.

His research interests cover the micro/nano-structured functional films, novel solid lubrication coatings and their applications in engine, M/NEMS and space technology. He has published over 100 papers in international journals such as Carbon, Applied Physics Letters, Tribology Letters, Wear and Tribology International, which received more than 1,000 citations. 